\title{
Forensic psychiatry in Israel
}

\author{
H. Gordon, A. Zabow, L. Carpel and P. Silfen
}

In May 1995 a Conference on Forensic Psychiatry was held near Tel Avtv, to which psychiatrists and other health professionals specialising in forensic psychiatry from Britain and Israel and Palestinians from the West Bank were invited. Participants at the Conference took part in discussions on forensic psychiatry and visited a maximum security prison with a hospital wing at Ramleh and an Arab psychiatric hospital in Bethlehem on the West Bank. On the days between Conference events, the British group visited Jerusalem and the Dead Sea and became aware of the almost unique interflux between Muslim, Christian and Jewish religion and culture which underlies the historical evolution of this area of the world. The modern social and political landscape is of course characterised by a violent confrontation between Arabs and Jews yet permeated now by a growing realisation of the need for peace and reconciliation, even if this has its ambivalent aspects at times. In this context the participation of Jewish and Arab health professionals together is a sign that ultimately medical and health care has its untversal qualities which can bridge over or supersede the differences between nations that are so endemic to history.

For the British participants, funding for their travel expenses was afforded partly by Broadmoor Hospital as well as by the British Council which acknowledged the potential importance of the Conference. A private donation was also made by a firm in London called Hospital Plan Insurance Services.

The British consisted of consultant forensic psychiatrists and three clinical psychologists. These came from Broadmoor Hospital, The Raeside Clinic and St Nicholas' Hospital, Newcastle. The Israeli participants included a number of senior psychiatrists including $\mathrm{Dr}$ Carlos Bar-El, President-Elect of the Israeli Psychiatric Association, Professor Michael Apter, Professor of Child Psychiatry at the University of Tel Aviv, and a prominent Israeli lawyer, David Pearlman.

In Bethlehem, the Medical Director, Dr Mustafa Mujahed and the deputy Medical Director, Dr Ibrahim Murad, introduced us to their medical nursing, clinical psychology and social work staff and described the work of the hospital. It is the only psychiatric hospital on the West Bank and prior to the 1967 war, it used to cover both the
West and East Banks of the Jordan River. It has achieved in establishing community psychlatric clinics in other West Bank towns including Ramallah, Nablus and Jenin. The hospital previously accepted forensic patients presenting with a high level of dangerousness, however, since the late 1980 s this has become increasingly difficult due to a reduced security presence following the intifada and the police being deployed elsewhere. In order to revive its ability to take forensic cases, it is hoped that as more areas of the West Bank become autonomous, the Palestinian police will be available to provide security.

At present there are no equivalents of Britain's Special Hospitals in either Israel or on the West Bank or Gaza. It is possible that such facilities may be established in Israel in the near future. However, the debate as reflected in the Reed Committee in Britain is also pertinent to Israel where there is not a full consensus as to whether such facilities should be centralised or dispersed into smaller units attached to general psychiatric hospitals.

Unlike Britain, psychiatric wards in Israel prisons are legally designated as hospitals and operate within the Ministry of Health according to Israel's mental health legislation. This has advantages that prisoners with mental lliness can be relatively easily transferred to a hospital ward but has the disadvantage that such prisoners should really be in hospital, not in prison. Nonetheless, Ramleh Prison seemed to be providing effective psychiatric care for its mentally ill patients, both male and female, as well as providing expert opinions on complex forensic psychiatric cases. A notable contribution at Ramleh Prison is made by a group of professionals known as clinical criminologists. Whereas criminology in most other countries has been essentially an academically based profession, in Israel it has developed as a combined clinical and research based discipline.

In Israeli law, compulsory hospitalisation can be undertaken only for those regarded as mentally ill or mentally impaired. There is no provision to detain those designated as psychopaths who can however recetve treatment voluntarily. Notwithstanding, in Ramleh Prison there was also a prison department for drug and alcohol abuse which has become a growing problem in Israel. 
There are also no medium secure units in Israel, though the general psychiatric hospitals do have locked wards. Most psychiatric units in Israel integrate male and female patients and staff, although this does cause some tension between health professionals and orthodox Jewish law.

A range of issues were debated at the Conference, with a sharing of experience from a clinical, psychodynamic and legal perspective. Sessions covering the assessment and treatment of sex offenders reflected the particular contributions of psychotherapy and appropriate medication to the understanding of psychopathology and the reduction of libido. A study of adolescents who kill in Israel sought to emphasise the importance of evaluating aggession as part of a mood disorder. Given the history in Britain of the role of the IRA and in Israel of the Arab-Israel conflict, it is known that in both areas of the world false confessions by defendants may occur. It was clearly in the interests of the police. judiciary and psychiatrists to be aware of the clinical and environmental factors which can impact on a confession, especially in high profile cases where there is public pressure on the police to obtain a conviction. The need to evaluate dangerousness in patients with personality disorder was also outlined, using both clinical assessment as well as various risk assessment schedules currently being researched. Complimenting these sessions were case presentations of the first known serial killer in Israel, followed by that of a man in a British Special Hospital involved in four homicides as part of one episode.

The Conference was felt to be a considerable success by all the participants. It is hoped that improved links can be developed between Britain and Israel and Palestinian colleagues and indeed with colleagues in the neighbouring states of Jordan, Egypt and Syria. A further conference in Britain is currently under consideration.

*Harvey Gordon, Consultant Forensic Psychiatrist, Broadmoor Hospital, Crowthorne, Berkshire RG45 7EG, England: Aubrey Zabow, Regional Psychiatrist, Beersheva Mental Health Care Centre, Beersheva, Israeli Leslie Carpel, Consultant Psychiatrist, Assad Harofeh Hospital, Tsrifin, Israel; and Peter Silfen. Professor of Clinical Criminology, Beer Yacov, Affliated to Tel Aviv University, Israel

*Correspondence 